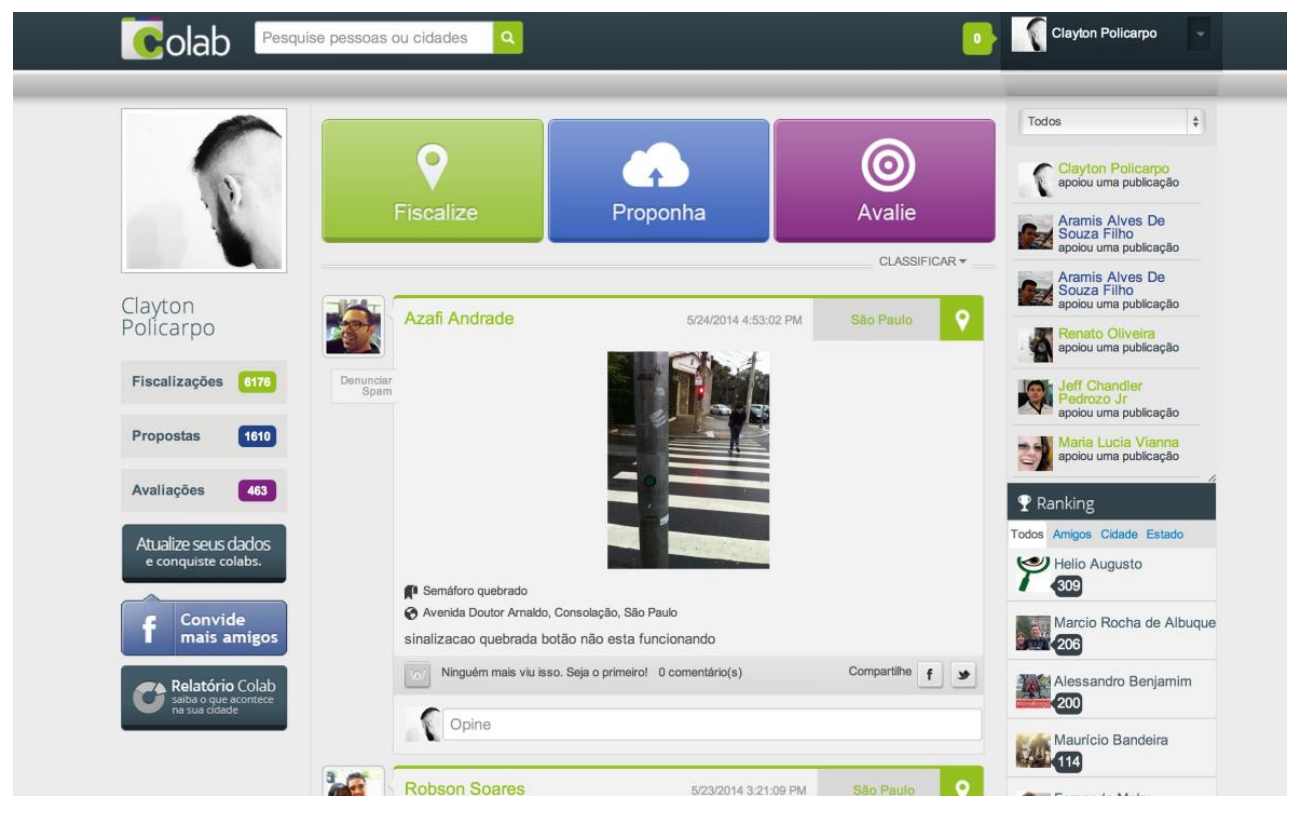

\title{
Rede social, colaboração e mobilidade: o caso do aplicativo urbano Colab no Brasil.
}

Social networking, collaboration and mobile: the case of the urban app Colab in Brazil.

\section{Resumo}

Alexandre Campos Silva ${ }^{1}$

Clayton Policarpo ${ }^{2}$

São várias as alternativas, embora muitas vezes se manifestem de forma discreta, que surgem com o intuito de integrar o cidadão à cidade e seus problemas. É notório que as TICs ${ }^{3}$ desempenham um papel fundamental neste processo, dado o seu caráter ubíquo cada vez mais reforçado pela disseminação de dispositivos móveis e locativos. Assim, o presente trabalho propõe uma análise dos modos de intervenção na metrópole contemporânea pautada pela informação, tendo como estudo a rede social $\operatorname{Colab}^{4}$.

Palavras-chave: cidade conectada, Colab, rede social, mobilidade, políticas públicas

\section{Abstract}

There are several alternatives, though they often manifest themselves discreetly and arise in order to integrate citizens to the city and its problems. It's clear that ICTs (Information and Communications Technology) plays a fundamental role in this process, given its omnipresent increasingly reinforced by the spread of mobile and rental devices. Thus, this current work proposes an analysis of the kind of intervention in the contemporary metropolis ruled by information, using the example of the social network Colab.

Keywords: connected city, Colab, social networking, mobile, public politics

1 Alexandre Campos Silva (alesilva@pucsp.br) é professor do programa de pós-graduação em Tecnologias da Inteligência e Design Digital da PUC-SP. Endereço: Rua Caio Prado, 102, São Paulo-SP, CEP: 01303-000.

2 Clayton Policarpo (clayton.policarpo@gmail.com) é mestrando em Tecnologias da Inteligência e Design Digital, PUC-SP.

${ }^{3}$ Adotamos o termo TIC, para nos referirmos às Tecnologias da Informação e Comunicação. Em inglês, ICT Information and Communications Technology.

4 Projeto desenvolvido pela empresa pernambucana Quick, disponível em <http://www.colab.re> Acessado em maio de 2014. 


\section{Introdução a cidade conectada}

Formas e artefatos comunicacionais operam na transformação dos espaços de sociabilização, desde o surgimento das primeiras cidades até as metrópoles contemporâneas. A constante evolução nos meios comunicativos modifica nossa maneira de perceber o entorno e se relacionar com ele: tecnologias digitais, ambiente e sujeito se permeiam como componentes integrantes de uma nova paisagem pós-urbana. ${ }^{5}$ Como decorrência de um crescente fluxo de informações, cada vez mais acessíveis, possibilitadas pela introdução da rede e a disseminação de dispositivos móveis, as concepções dualistas entre espaço virtual e físico, e a dicotomia de entrada e saída do ciberespaço, são dissipadas e se abrem em uma nova mesclagem irreversível de características intrínsecas a universos virtuais e ao mundo concreto, essas fissuram moldam espaços de intesecção entre o presencial e o virtual, suturas definidas por estudiosos sob os nomes de espaço instersticial ${ }^{6}$ (Santaella, 2010, p. 99), território informacional (LEMOS, 2011, p. 23) e espaço híbrido (SOUZA e SILVA, 2006 apud SANTAELLA, 2010, p. 99) e espaço ATÓPICO (Di FELICE, 2009, p. 221).

Pensar a cidade contemporânea é analisar as camadas que a constitui. Ao longo da história do urbanismo a introdução de novos objetos e novas tecnologias se sobrepuseram, e permitiram a coexistência de diferentes tempos na metrópole do século XXI.

O desenvolvimento de equipamentos móveis de comunicação, que passam a concentrar recepção, criação e distribuição de conteúdo somado a computação pervasiva, possibilita a transposição de funções antes restritas a pontos específicos, para o território urbano, a cidade comunicante não mais se conforma como mero receptáculo de ações ou uma via de mão única para exposição de informações. A espacialidade que surge se redesenha e inova a cada resposta, e no espaço social se alimenta de apropriações e de ações que a integram em uma escala mundial, redefinindo a noção de habitar a metrópole, e reconfigurando a percepção da própria paisagem.

Habitar a cidade contemporânea é conduzir-se por arquiteturas fluídas. Lemos (2011, p. 16) descreve três dimensões fundamentais da mobilidade: a do pensamento - a desterritorialização por excelência, conceito projetado por Deleuze e Guatarri (1997) -; a física (corpos e objetos) e a informacional-virtual. Comunicar é deslocar. Torna-se

\footnotetext{
${ }^{5}$ Conceito apresentado por Massimo Di Felice em seu livro Paisagens Pós-urbanas - O fim da experiência urbana e as formas comunicativas do habitar. São Paulo: Annablume, 2009.

${ }^{6}$ No decorrer do trabalho, optamos por utilizar o termo espaço instersticial, uma vez que este parece abordar de forma mais efetiva dissoluções entre espaços físicos e ciberespaço.
} 
inerente a natureza humana vivenciar o espaço ampliado e deslizar por entre os diversos territórios criados pelo constante estado de mobilidade. Pensar a cidade, dentro deste contexto, adquire uma nova dimensão.

\section{Colab, uma rede social para a cidade}

O Colab, iniciado em Recife, em março de 2013, já nas duas primeiras semanas após sua implantação recebeu cerca de 570 postagens. A introdução da rede na cidade de São Paulo se deu na sequência, no dia 16 de abril do mesmo ano. A expansão do projeto segue na velocidade habitual dos furacões catalisadores de tendências que surgem via web, hoje a rede atua em 1247 municípios de todo Brasil com quase 30 mil usuários. Um dos seus principais objetivos é estabelecer uma linha direta de comunicação entre população e poder público.

Dentre as premiações de destaque conquistadas desde sua fundação, o projeto foi vencedor no prêmio AppMyCity ${ }^{7}$ de 2013, da Organização New Cities Foundation, que anualmente elege o melhor aplicativo urbano do mundo, que através de ferramentas que sejam rápidas e fáceis de usar, repense a cidade e proponha novas maneiras de torna-las melhores. A empresa de investimento em negócios digitais A5 Internet Investments ${ }^{8}$ disponibilizou um subsídio de R \$ 3,5 milhões para expansão do projeto no mercado, em especial no que diz respeito à adesão de novas cidades, aquisição de tecnologias e ações de marketing. ${ }^{9}$

Desenvolvido como um site e um aplicativo para smartphone (disponível para as plataformas operacionais Android ou $i O S$ ), possibilita que o usuário da rede social comunique e se integre a respeito dos problemas de sua cidade, criando uma rede de engajamento em nível local.

\footnotetext{
${ }^{7}$ Prêmio App My City disponível em <http://appmycity.org/〉. Acessado em junho de 2014.

8 Empresa de investimentos em negócios digitais A5 Internet Investiments, disponível em <http://www.a5.com.br/>. Acessado em junho de 2014.

9 Matéria publicada na revista eletrônica Startupi, em 31 de março de 2014, disponível em $<$ http://startups.ig.com.br/2014/colab-re-rede-voltada-melhorias-nas-cidades-ganha-aporte-de-r-35milhoes/>. Acessado em junho de 2014.
} 
Colab Pesquise pessoas ou cidades a

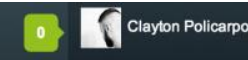

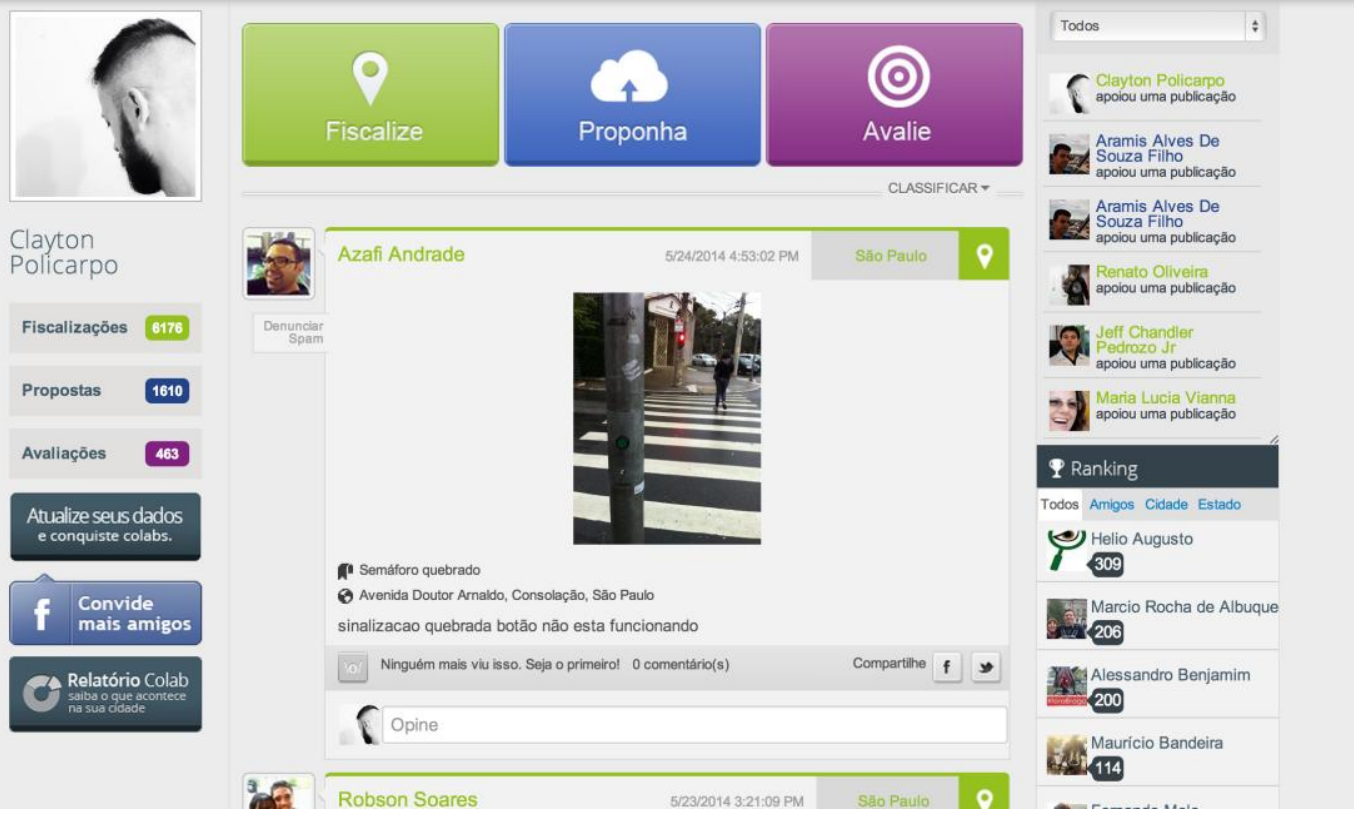

Figura 1: Página inicial do perfil de usuário do Colab na web, disponível em <http://www.colab.re>. Acessado em junho de 2014.

Colab Pescuise pessoas ou didades a $a$
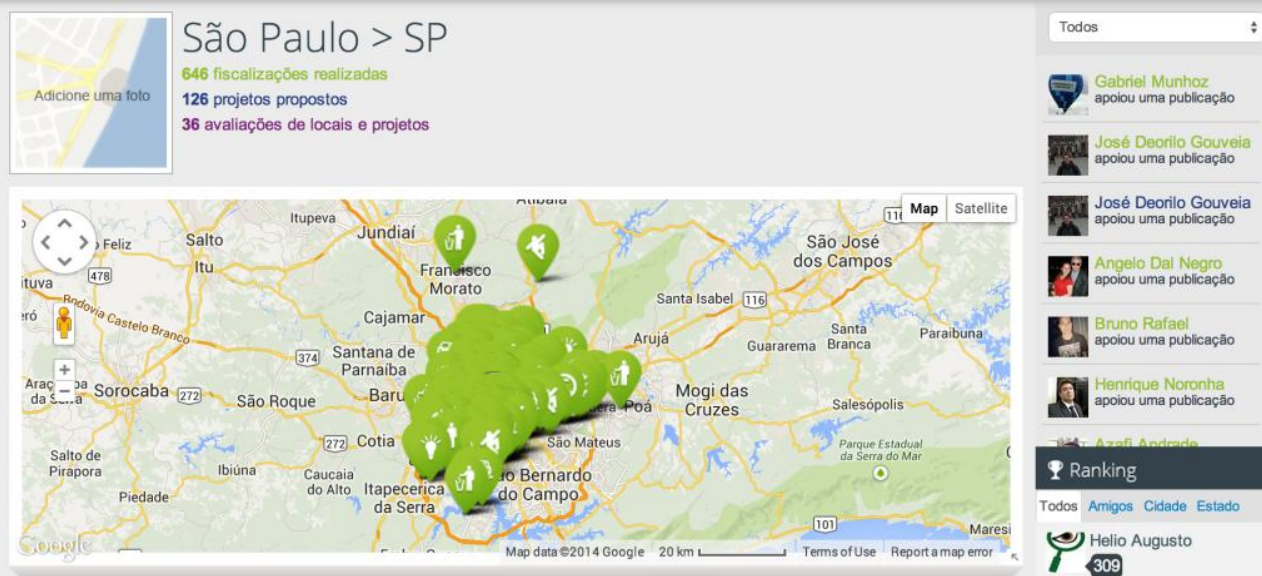

F) Gabriel Munhoz uma publicą̧ăo

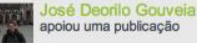

IXixid José Deorilo Gouveia

9.1. Angolo Da nal Nugro

3. Bruno Rafael

9. Henrique Noronha

Ranking

rodos Amigos Cidade Estado

(C) Helio Augusto

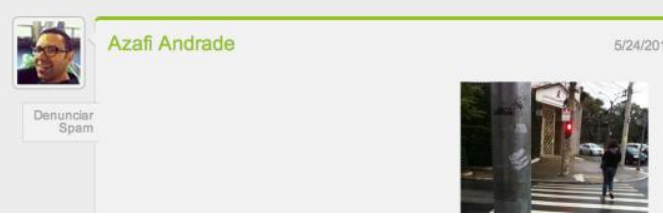

5. Marcio Rocha de Albuque

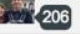

1.4. Alessandro Benjamim

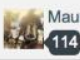

Figura 2: Página inicial de visualização por cidade, disponível em <http://www.colab.re>.

Acessado em junho de 2014. 


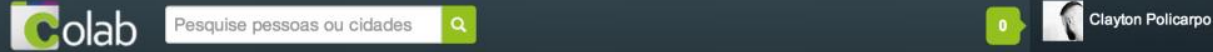

\begin{tabular}{|c|c|c|c|c|c|c|}
\hline Tipo & & Categoria & & Local & & Período \\
\hline Todos & $\hat{\sim}$ & Todos & $\hat{\sim}$ & São Paulo & 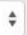 & $\mathrm{mm} / \mathrm{dd} / \mathrm{yyy} y$ \\
\hline & & & & São Paulo & $\hat{\sim}$ & $\mathrm{mm} / \mathrm{dd} / \mathrm{yyyy}$ \\
\hline
\end{tabular}

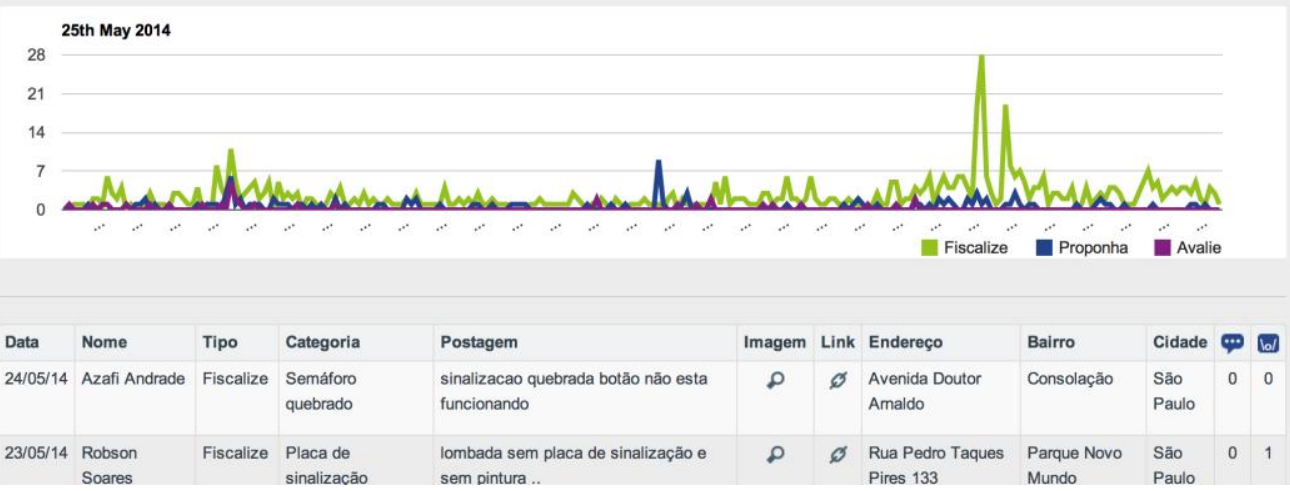

Figura 3: Página de visualização de gráficos, disponível em <http://www.colab.re>.

Acessado em junho de 2014.

\section{Colab Pesquise pessoas ou cidades a}

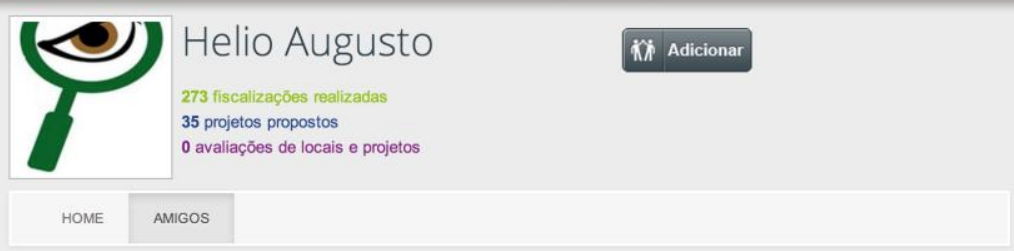

Todos

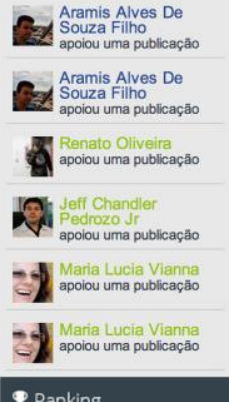

Ranking

rodos Amigos Cidade Estado

(5) Helio Augusto

Fin Marcio Rocha de Albuque

1) Aless

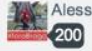

6.4. 


\section{Golab Pesquise pessoas ou cidades a}

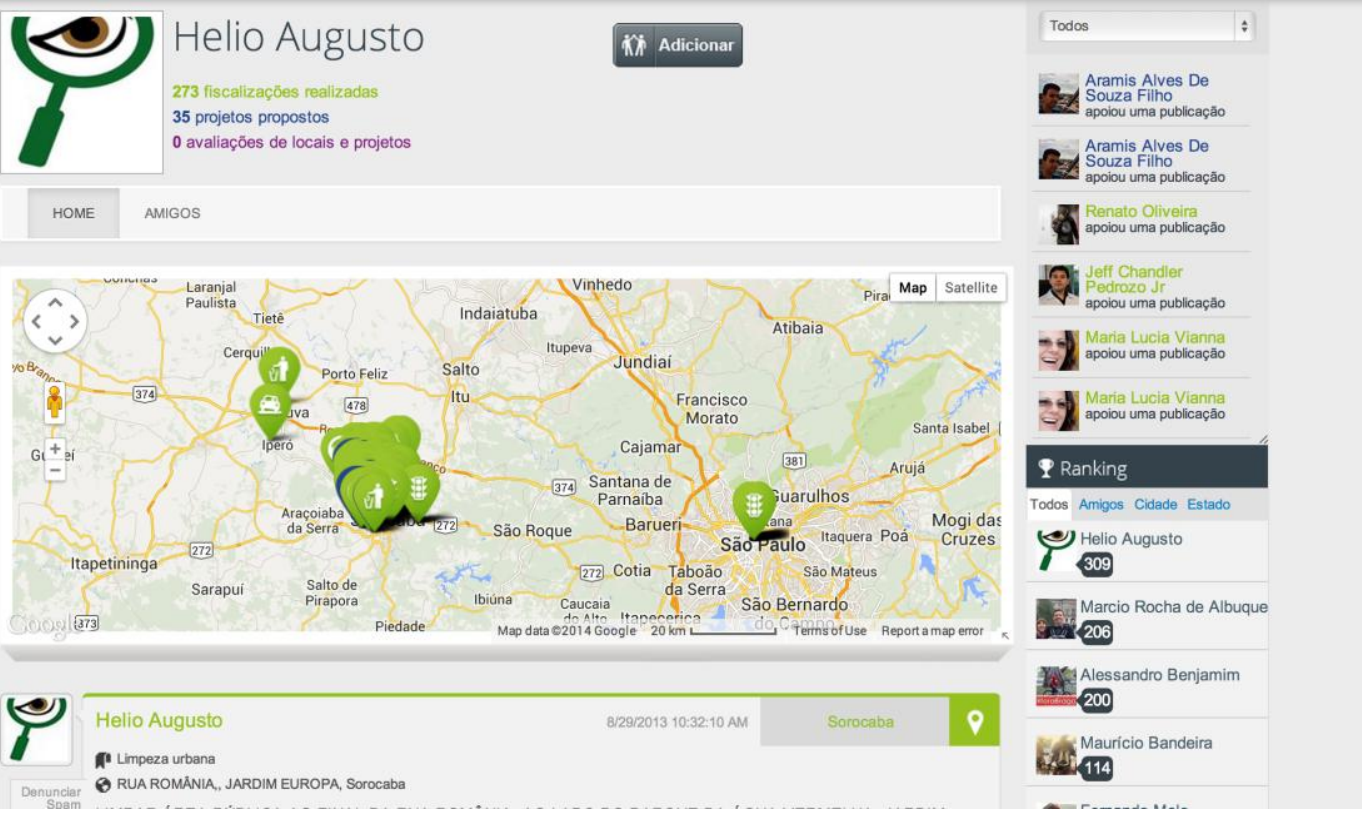

Figura 4 e 5: Perfil de um usuário ativo na rede, líder no ranking geral proposto, disponível em <http://www.colab.re>. Acessado em maio de 2014.

Ao permitir o cadastro do usuário/interator através da conta da rede social Facebook, a plataforma elimina barreiras antes impostas por sites gerenciados pelo poder público onde as especificidades exigidas intimidam a ação do cidadão, ao tempo que também define um perfil de usuário já integrado e habituado à linguagem da rede. Diferente de outras plataformas sociais, aqui as afinidades que aproximam dizem respeito a questões urbanas, mobilizações, denúncias e levantamento de possíveis soluções. Em seu conceito e estrutura, o projeto em muito se assemelha as redes sociais de grande adesão. É possível se conectar a outros usuários, avaliar positivamente as postagens, comentar e retransmitir via Facebook e Twitter. É utilizado um recurso de gamificação que se estende do aplicativo e site, na medida que o usuário interage na plataforma (através de postagens, comentários), são feitas pontuações. O recurso adotado, cria um ranking entre os usuários ativos, dividido nas categorias: geral, amigos, cidade e estado. 


\section{Colabre oqueé? Download App Fale Conosco Entrar usando Facebook f}

\section{Fiscalize, Proponha e Avalie!}

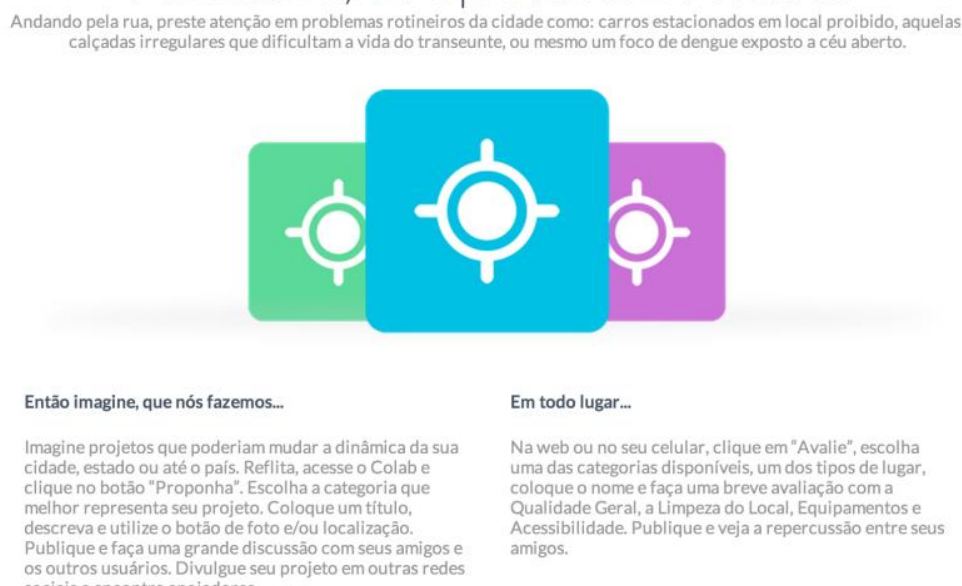

Figura 6: Pilares do projeto Colab. Disponível em <http://www.colab.re>. Acessado em junho de 2014.

Alçado em três pilares fundamentais: fiscalização, proposta e avaliação, o Colab permite a interação crítica do cidadão em diferentes níveis. É possível anexar imagens as postagens que, sendo geolocalizáveis, determinam as informações contidas no mapa exibido na página de perfil do usuário/interator. Cada um dos pilares é composto por subtemas, o que direciona as postagens dos usuários para assuntos específicos. A categoria "fiscalize", atualmente é composta por 26 temas; a categoria "proponha" permite apresentar idéias em 12 diferentes temas; já a aba de avaliações, onde seria possível avaliar serviços e equipamentos públicos, está temporariamente desativada.

Como uma ação durante a realização da Copa do Mundo de 2014, no Brasil, os pilares Fiscalize e Avalie no aplicativo para dispositivos móveis, incorporaram novas categorias, no intuito de avaliar as cidades sede dos jogos. São 14 categorias em Fiscalize, relacionadas a infraestruturas de transporte e estádios, e 3 categorias em Avalie que propõem qualificar aeroportos, estádios e rodoviárias. 


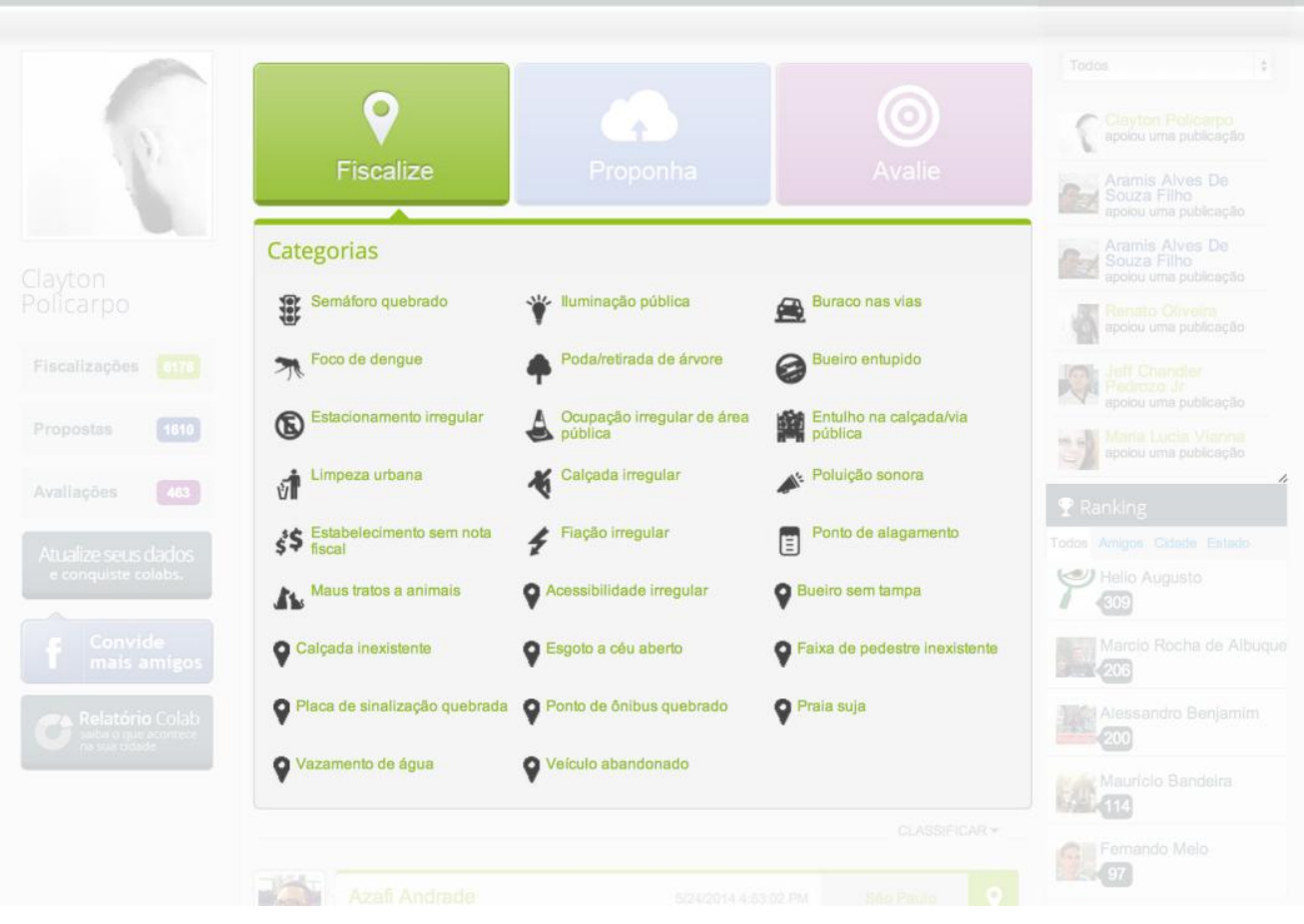

Figura 7: Tela que precede as postagens na categoria fiscalize, onde são mostrados temas. Disponível em <http://www.colab.re>. Acessado em junho de 2014.

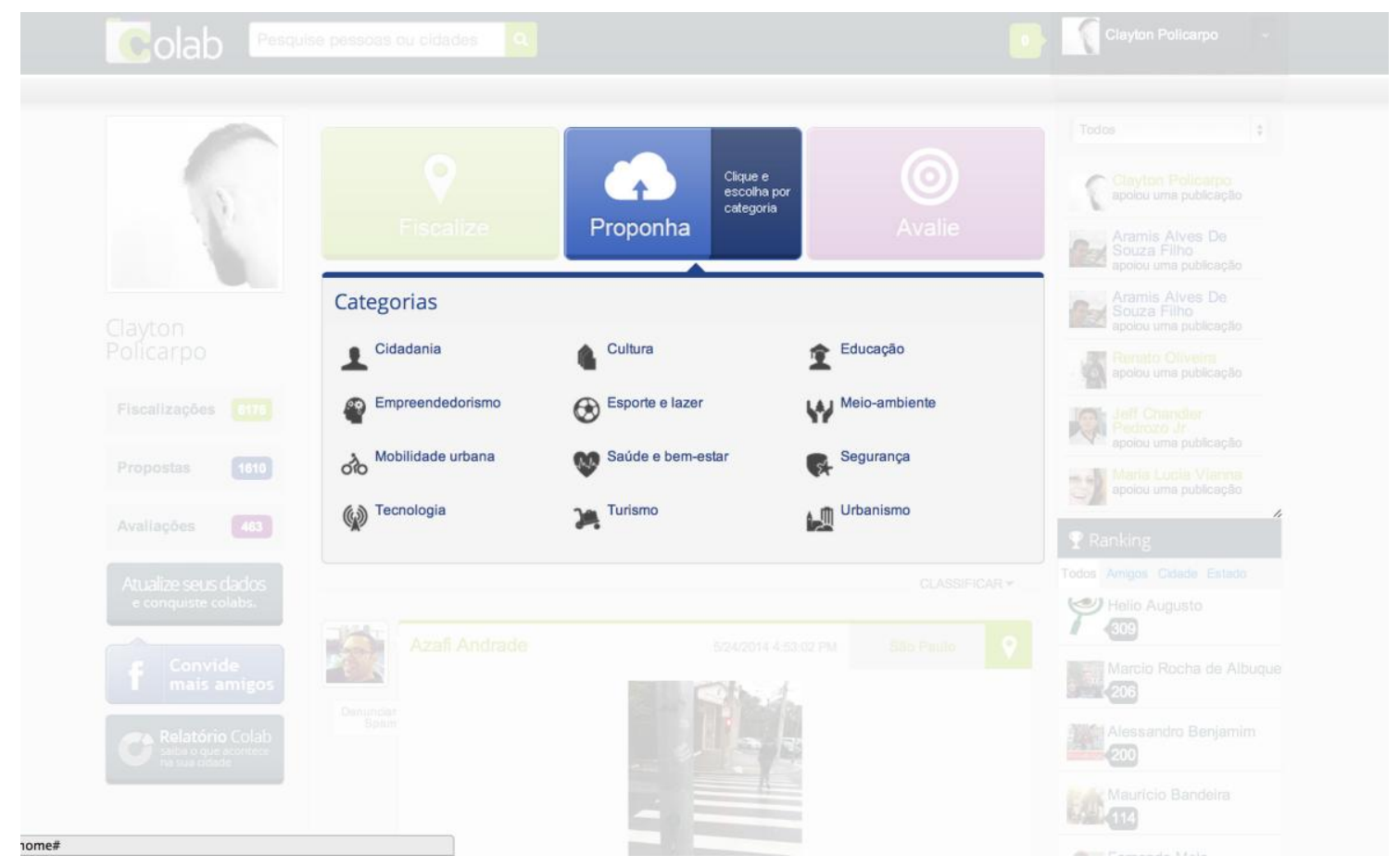

Figura 8: Tela que precede as postagens na categoria proponha, onde são mostrados temas. Disponível em <http://www.colab.re>. Acessado em junho de 2014.

A visualização de informações, tanto na página inicial, quanto no perfil visitado segue o padrão de timeline, aderido pelas principais redes sociais, que mostra as 
informações a partir das postagens mais recentes. Para visualizar as publicações, podemos filtrar por localização, país, estado, cidade ou grupo de amigos; modalidade, dentro dos três pilares propostos; relevância, publicações que proporcionaram maior repercussão, ao serem avaliadas e receberam maior numero de comentários.

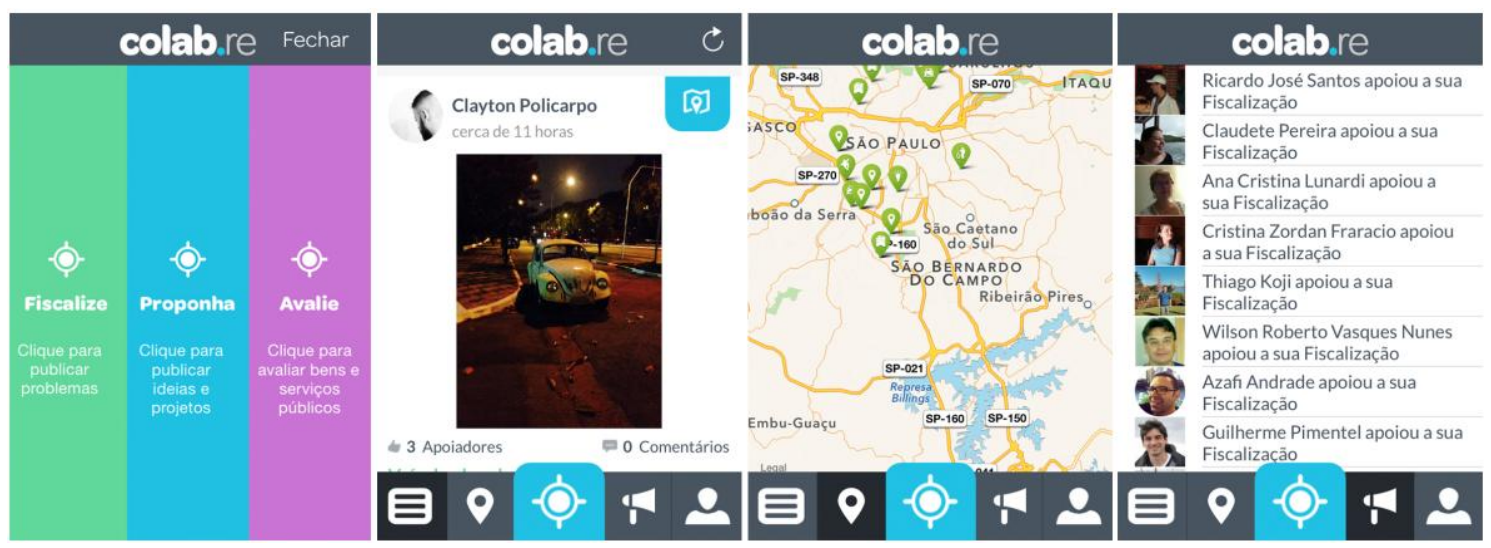

Figura 9: Telas do aplicativo Colab para dispositivos móveis, disponível em: Aplicativo mobile. Acessado em junho de 2014

O Colab é uma interface que traduz uma cidade em estado de controle. Ora se tecnologias de informação, em especial as chamadas mídias locativas, trazem em sua essência um apelo para a vigilância digital, chamado por Santaella (2010, p. 157) de regime por rastreamento, dispositivos móveis e tecnologias GPS $^{10}$ apontam para uma pressuposta vigilância do território, onde o cidadão munido de dispositivos moveis dotados de acesso a web, câmera fotográfica e tecnologia de geolocalização, se atenta para divergências no meio urbano. No momento que a ação na rede-social apoia-se no testemunho registrado dos acontecimentos no espaço, o usuário se vê como agente fiscalizador. Dispositivos móveis "ampliam sobremaneira as formas de controle, monitoramento e vigilância, tornando-as mais difusas, performáticas (banco de dados eletrônicos) e invisíveis.” (LEMOS apud SANTAELLA, 2010, p. 158).

O rastreamento pelas mídias móveis é ubíquo e pulverizado. Lugares conectados entre si são pontos de um fluxo contínuo de vigilância. $\mathrm{O}$ movimento não é um meio para se evadir da vigilância, bem pelo contrario, tornou-se o próprio meio da vigilância (BENNET e REGAN, apud SANTAELLA, 2010, p. 159).

\footnotetext{
${ }^{10}$ Global Positioning System (Sistema de Posicionamento Global), é um elaborado sistema de satélites e outros dispositivos que tem como função básica prestar informações precisas sobre o posicionamento individual no globo terrestre.
} 
Ao se apropriar destes espaços intersticiais, o Colab rompe com os conceitos de espaço concreto e virtual e passa a exercer sua ubiquidade, transitando entre territórios de conexão e desconexão. A partir de então, incorporar novas linguagens e se estender seu alcance para outras plataformas se torna um movimento natural.

Para reforçar a participação e divulgar as ações do projeto, e no intuito de criar um canal de contato com os desenvolvedores o Colab, também possui uma página no Facebook $^{11}$. Com mais de dezenove mil seguidores, divulga ações de marketing, matérias sobre infraestrutura, campanhas de mobilização urbana e a respeito do alcance e repercussão do projeto pelo mundo.

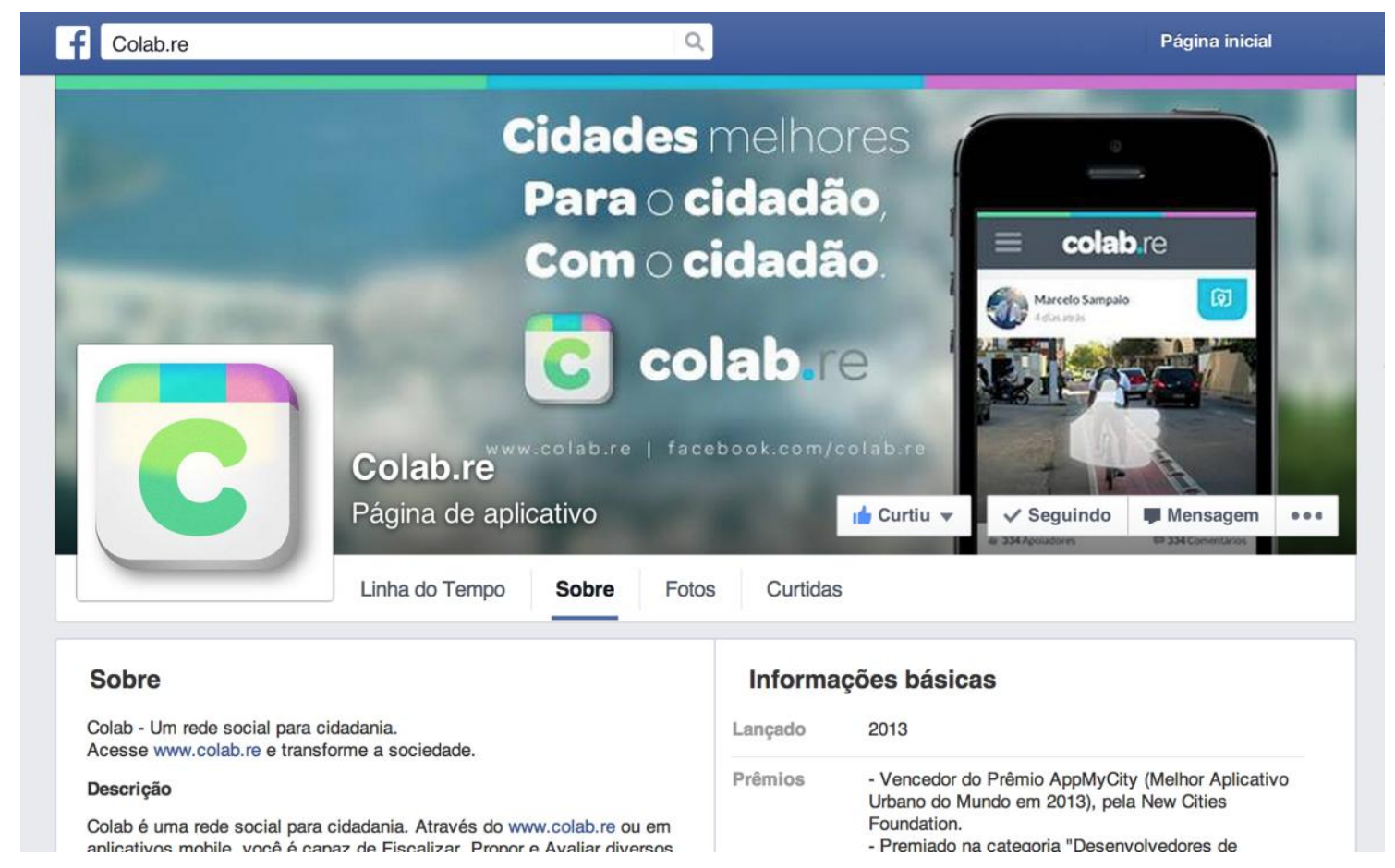

Figura 10: Página da rede social Colab no Facebook, disponível em <https://www.facebook.com/colab.re>. Acessado em julho de 2014.

11 Página da rede social Colab no Facebook, disponível em <http://www.facebook.com/colab.re>. Acessado em maio de 2014. 


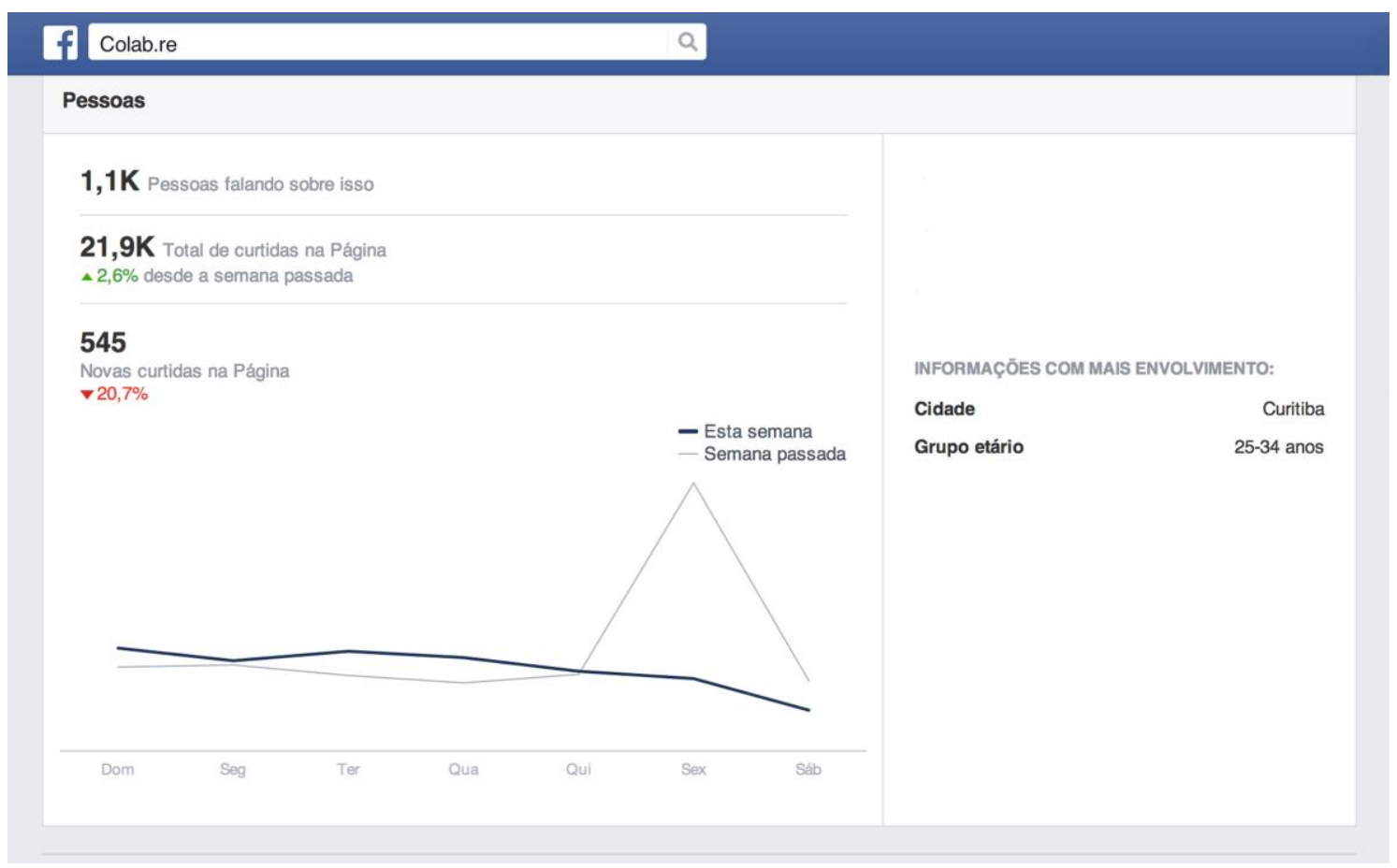

Figura 11: Gráficos de acesso da página Colab no Facebook, disponível em <https://www.facebook.com/colab.re>. Acessado em julho de 2014.

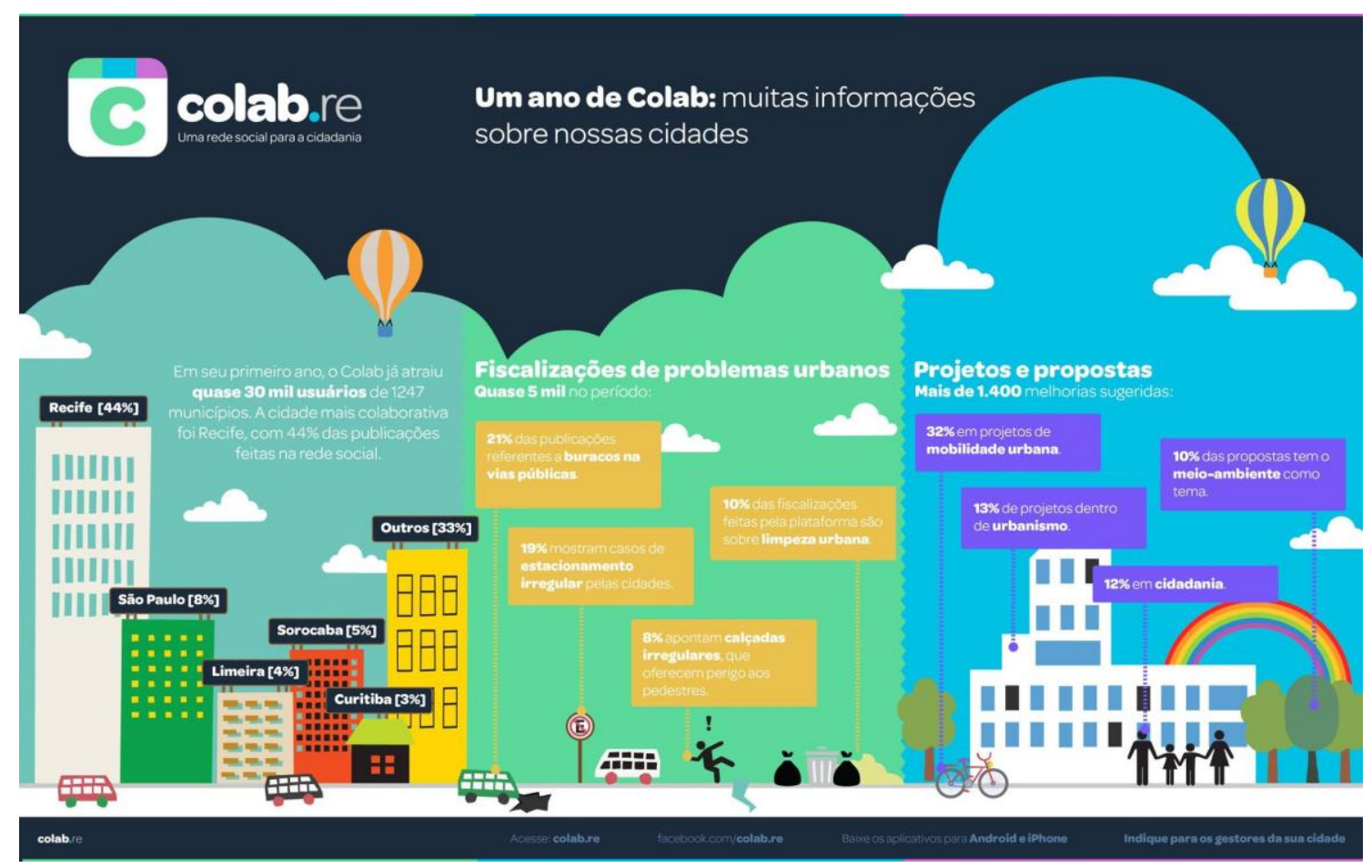

Figura 12: Relatório de atividades divulgado pelo Colab.

disponível em <https://www.facebook.com/colab.re>. Acessado em junho de 2014.

\section{Uma ponte entre o cidadão e o poder público}


De acordo com Gustavo Maia, um dos idealizadores do projeto, "a legitimidade da ferramenta depende também da independência do poder público e da não-vinculação política". ${ }^{12}$ É fato que associação a alguma prefeitura ou partido político, poderia comprometer a integridade da proposta, para se manter a empresa pretende buscar financiamento em propagandas na própria plataforma e através de investidores.

No princípio da plataforma, as denúncias encaminhadas via aplicativo e site, eram entregues pela equipe aos órgãos competentes, o que não garantia a geração de ações, embora fosse evidente a criação de um canal de comunicação entre a população, horizontalizando o sentido de propriedade com o meio urbano.

Embora seja descartado um financiamento por meio dos órgãos públicos, o grupo em uma de suas atualizações recentes, desenvolveu ferramentas de gestão que são oferecidas às prefeituras e atuam como plataformas complementares ao principal objetivo da rede, que é criar uma ponte entre cidadão e poder público. Deste modo a gestão dos municípios poderá ter acesso às informações e comentários divulgados pelos cidadãos, e com base nestas informações solucionar problemas e ter um retorno de sua gestão. Curitiba foi a primeira cidade a adotar o sistema, em abril de 2014. De acordo com publicação na página do Facebook já são dez cidades em todo o país que adotaram a rede como canal oficial de comunicação entre prefeitura, órgãos responsáveis e cidadãos. $^{13}$

12 Em entrevista ao jornal Estado de São Paulo em 18 de abril de 2013, disponível em <http://www.estadao.com.br/noticias/cidades,site-encaminha-reclamacoes-de-cidadaos-a-orgaospublicos, 1022670,0.htm> Acessado em 2013.

${ }^{13}$ As cidades são: Curitiba-PR, Teresina-PI, Cuiabá-MT, Foz do Iguaçu-PR, Bauru-SP, RondonópolisMT, Petrolina-PE, Tibau-RN, São Sepé-RS, Maracaju- MS <https://www.facebook.com/colab.re?fref=ts> Acessado em junho de 2014. 


\section{Como a prefeitura enxerga e interage}

\section{monitor.colab.re - um painel de gestão completo e sem custo}

. Login individual para equipe da

prefeitura

. Página de pendências

- Geração de protocolos

. Disparo automático para órgão

responsável

. Comunicação com todos os envolvidos

na publicação

.Página de soluções

.Mapa com filtros em

tempo real

.Estatísticas por categorias, data, etc

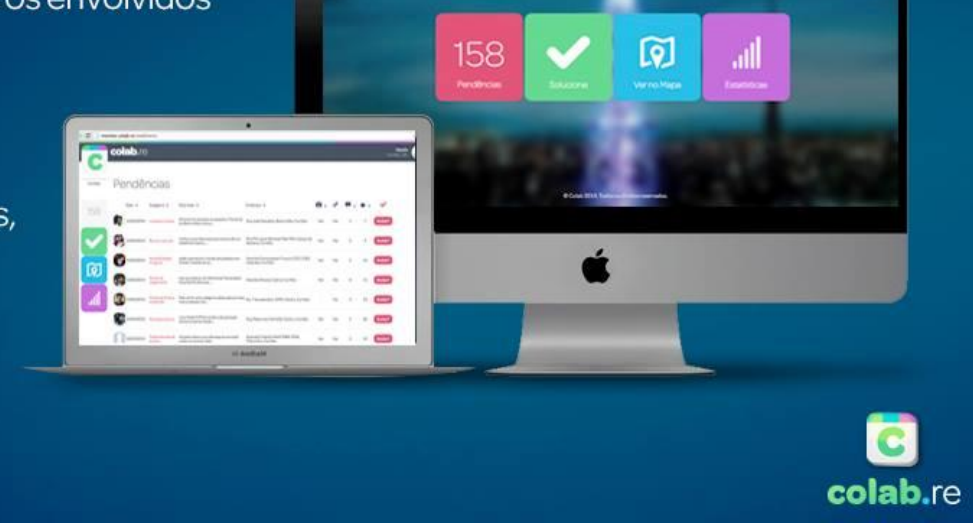

Figura 13: Divulgação da plataforma para órgãos públicos, disponível em <http://www.colab.re>.

Acessado em junho de 2014.

O fato é que no caso de uma ideia que nasceu com o intuito de se efetivar no meio urbano, não se podem descartar o papel desempenhado pelas políticas públicas. As repercussões proporcionadas pelo avanço das novas tecnologias de comunicação, fez com que tais iniciativas tenham se tornado agenda obrigatória nos programas de ações do poder público. É evidente que as TICs assumem papel fundamental nas novas sociedades, todavia, são muitas as barreiras que se armam entre as reflexões teóricas e o campo de aplicabilidade. Políticas públicas e desenvolvimento tecnológico divergem na velocidade em que caminham, gestores e urbanistas apresentam receosos quanto ao uso de novas tecnologias e por vezes desconhecem os impactos sócio-culturais que estas geram.

Se, em primeiro momento estratégias públicas que visam equipar a cidade de tecnologias de informação possam soar como mero oportunismo e marketing político, tais ações tornam-se justificáveis na medida em que a defasagem do acesso a informação, denota um retrocesso na gestão vigente. Milton Santos exemplifica a pobreza, para além de dados estatísticos com ênfase nas definições de miséria ou renda, 
como uma definição política que tem a ver com os objetivos que uma sociedade determina para si (SANTOS, 1979). Ora, e se vivemos na sociedade do conhecimento, onde a informação é determinante na formação do sujeito, o acesso à rede e a ferramentas que propiciem a interação entre homem e meio, devem fazer parte de qualquer caráter de pobreza. Deste modo, se fazem necessárias políticas públicas voltadas ao desenvolvimento no setor.

Contudo, gestores públicos, urbanistas e profissionais que se dedicam a mediar os problemas diários e palpáveis das metrópoles, se veem diante da dificuldade em superar o paradigma da intangibilidade das estruturas de TICs, dado que em sua essência, estas são compostas por elementos difíceis de serem precisados, o que por muitas vezes resulta na não compreensão por parte de políticas públicas das relações reestruturadas e definidas entre o cidadão e o meio (FIRMINO, 2011, p. 15).

\section{Considerações finais}

Com a constante disseminação de dispositivos móveis de produção, recepção e difusão de linguagem, a experiência de percorrer a cidade adere a múltiplas camadas e torna evidente o papel do cidadão como agente produtor de signos que se incorporam a urbe, e tornam-se capazes de transpor barreiras entre a cidade e suas representações, e aproximar gestores da população e suas necessidades.

O Colab vem se firmando como uma plataforma capaz de integrar o cidadão ao seu entorno imediato e com base no apoio de órgãos responsáveis promover melhorias na cidade. Um ano após seu lançamento, a rede conta com quase 30 mil usuários distribuídos em 1247 municípios em todo Brasil, dos quais de acordo com informações divulgadas pelo grupo de desenvolvedores, 10 cidades já utilizam a rede como canal oficial para contato com o cidadão, driblando dificuldades da iniciativa pública em aderir as TICs.

Com mais de 5 mil fiscalizações e 1400 melhorias sugeridas, a rede comprova que a adesão e engajamento dos usuários, reforça o potencial colaborativo observado na web 2.0, trazendo um ambiente de não-linearidade e interatividade. O que fica evidente, é que com a disponibilização de ferramentas que possibilitem uma intervenção no meio físico pelo cidadão comum são efetivamente abolidos os padrões rígidos criando caminhos diversos que rompem com os padrões hegemônicos de governo. A multiplicidade de conexões e de interatores, gera uma mobilização efetiva de competências, a chamada inteligência distribuída, inteligência coletiva (LÉVY 1997, p. 28) 


\section{Referências Bibliográficas}

DI FELICE, Massimo. 2009. Paisagens Pós-urbanas: O fim da experiência urbana e as formas comunicativas do habitar. São Paulo: Annablume.

FIRMINO, Rodrigo José. 2011. Cidade Ampliada - desenvolvimento urbano e tecnologias da informação e comunicação. São Paulo: Ecidade.

LEMOS, André. 2011. "Cultura da Mobilidade". In: BEIGUELMAN, Giselle. LA FERLA, Jorge. Nomadismos Tecnológicos. São Paulo: Editora Senac.

LÉVY, Pierre. 1997. As Tecnologias da Inteligência. São Paulo: Editora 34.

PRIMO, Alex. 2011. Interação mediada por computador. Porto Alegre: Editora Sulina.

SANTAELLA, Lucia. 2010. A ecologia pluralista da comunicação. São Paulo: Paulus.

SANTOS, Milton. 1979. Economia Espacial: críticas e alternativas. São Paulo: Editora da Universidade de São Paulo. 
Para citar essa obra:

SILVA, A. C. POLYCARPO, C. Rede social, colaboração e mobilidade: o caso do aplicativo urbano Colab no Brasil. In: RUA [online]. 2014, no. 20. Volume 1 - ISSN 1413-2109. p. 17 - 31. Consultada no Portal Labeurb - Revista do Laboratório de Estudos Urbanos do Núcleo de Desenvolvimento da Criatividade.

http://www.labeurb.unicamp.br/rua/

Capa: Página inicial do perfil de usuário do Colab na web, disponível em <http://www.colab.re>. Acessado em junho de 2014.

Laboratório de Estudos Urbanos - LABEURB

Núcleo de Desenvolvimento da Criatividade - NUDECRI

Universidade Estadual de Campinas - UNICAMP

http://www.labeurb.unicamp.br/

Endereço:

LABEURB - LABORATÓRIO DE ESTUDOS URBANOS

UNICAMP/COCEN / NUDECRI

CAIXA POSTAL 6166

Campinas/SP - Brasil

CEP 13083-892

Fone/ Fax: (19) 3521-7900

Contato: http://www.labeurb.unicamp.br/contato 